Table 1. Unadjusted means (SD) of SF-36 PCS and MCS

\begin{tabular}{lcccc}
\hline & Months & RA (mean (SD)) & PsA (mean (SD)) & p-value \\
\hline SF-36 PCS & 0 & $31.3(10.0)$ & $31.6(9.7)$ & 0.31 \\
& 3 & $36.7(11.1)$ & $37.3(11.1)$ & 0.16 \\
SF-36 MCS & 6 & $37.9(11.3)$ & $38.1(10.9)$ & 0.64 \\
& 0 & $45.6(11.6)$ & $46.3(11.7)$ & 0.08 \\
& 3 & $48.1(10.9)$ & $48.3(10.9)$ & 0.60 \\
& 6 & $48.8(10.8)$ & $49.1(10.7)$ & 0.49 \\
\hline
\end{tabular}

Table 2. ANCOVA analyses with adjustment for age, gender and years since diagnosis

\begin{tabular}{lcccc}
\hline & Months & \multicolumn{2}{c}{ Estimated marginal means $(95 \% \mathrm{Cl})$} & P value \\
\cline { 2 - 4 } & & RA & PsA & \\
\hline SF-36 PCS & 0 & $32.3(31.9-32.7)$ & $31.6(31.0-32.2)$ & 0.06 \\
& 3 & $37.9(37.4-38.4)$ & $36.8(36.1-37.6)$ & 0.02 \\
SF-36 MCS & 6 & $39.3(38.8-39.9)$ & $37.6(36.9-38.4)$ & 0.001 \\
& 0 & $46.3(45.8-46.8)$ & $46.2(45.5-46.9)$ & 0.90 \\
& 3 & $48.3(47.8-48.9)$ & $48.3(47.6-49.0)$ & 0.92 \\
& 6 & $49.5(49.0-50.0)$ & $48.9(48.1-49.7)$ & 0.21 \\
\hline
\end{tabular}

Pfizer, UCB, Roche, MSD, BMS and Novartis., Speakers bureau: AbbVie, Pfizer, UCB, Roche, MSD, BMS and Novartis., G. Haugeberg: None declared, T. Kvien Consultant for: AbbVie, Biogen, BMS, Boehringer Ingelheim, Celltrion, Eli Lilly, Epirus, Janssen, Merck-Serono, MSD, Mundipharma, Novartis, Oktal, Orion Pharma, Hospira/Pfizer, Roche, Sandoz and UCB, Speakers bureau: AbbVie, Biogen, BMS, Boehringer Ingelheim, Celltrion, Eli Lilly, Epirus, Janssen, MerckSerono, MSD, Mundipharma, Novartis, Oktal, Orion Pharma, Hospira/Pfizer, Roche, Sandoz and UCB

DOI: 10.1136/annrheumdis-2017-eular.3154

\section{OP0110 ASSOCIATION OF PHARMACOLOGICAL BIOMARKERS WITH TREATMENT RESPONSE AND LONG-TERM DISABILITY IN PATIENTS WITH PSORIATIC ARTHRITIS: RESULTS FROM OUTPASS}

M. Jani ${ }^{1,2}, \mathrm{H}$. Chinoy ${ }^{1,2}, \mathrm{~A}$. Barton ${ }^{1,2}$ on behalf of Outcomes of Psoriatic Arthritis Study Syndicate (OUTPASS). ${ }^{1}$ NIHR Manchester Musculoskeletal Biomedical Research Unit, Manchester Academic Health Science Centre, Central Manchester Foundation Trust and University of Manchester; ${ }^{2}$ Centre for Musculoskeletal Research, University of Manchester, Manchester, United Kingdom

Background: Up to $40 \%$ of patients with inflammatory arthritis on TNF- $\alpha$ inhibitor (TNFi) treatment fail to respond either due to primary inefficacy or loss of response. One explanation is immunogenicity leading to the development of anti-drug antibodies (ADAb) and subsequent low drug levels. Few data exist on whether such pharmacological tests correlate with treatment response in psoriatic arthritis (PsA). The clinical utility of whether such tests should be incorporated into practice is in question.

Objectives: To identify (i) whether the presence of ADAbs/drug levels predict treatment response and disability in TNFi-treated PsA patients (ii) the factors associated with drug levels (iii) a drug level threshold for optimal therapeutic response.

Methods: 75 patients were available from the Outcomes of Treatment in PsA Study Syndicate (OUTPASS) [ $n=49$ adalimumab; $n=26$ etanercept], a national UK prospective observational cohort. Serum samples were collected at 3,6 and 12 months following initiation of TNFi therapy. ADAbs were measured using radioimmunoassay $(R \mid A)$ and random (non-trough) drug levels using ELISA assays at 3, 6 and 12 months. Disease activity (DAS28) scores were measured at each visit. Patient self-reported adherence to TNFi was measured at each timepoint. Generalised estimating equation (GEE) was used to test the association between ADAbs and drug levels, both biomarkers and treatment response [as assessed by change in DAS28 score between pre-treatment and 12 months post-treatment ( $\triangle \mathrm{DAS} 28)$ ], Health assessment Questionnaire (HAQ) and the association between longitudinal/baseline factors with drug levels.

Results: 264 serial samples were suitable for pharmacological testing ( $n=174$ adalimumab; $n=90$ etanercept). Mean age was $51 \pm 12$ years; $61 \%$ were female; median BMI 28.9 (IQR 26.0-34.9). 20\% ( $n=10 / 49)$ of adalimumab-treated patients were positive for ADAbs, but none were detected in etanercept-treated patients. There was no significant association between etanercept drug levels and $\triangle \mathrm{DAS}$ over 12 months $[\beta=-0.039(95 \% \mathrm{Cl}-0.31,0.23), p=0.77]$. Using GEE, adalimumab drug levels were significantly associated with $\triangle \mathrm{DAS} 28$ over 12 months $[\beta=0.055$ (95\% Cl: $0.011,0.099) \mathrm{p}=0.014]$ and inversely with HAQ scores over 12 months $[\beta=-0.022$ ( $95 \% \mathrm{Cl}:-0.043,-0.00063]$. $\triangle \mathrm{DAS} 28$ was not independently associated with ADAb level $[\beta=-0.0015(95 \% \mathrm{Cl}:-0.0031,0.000047), p=0.057]$. Adalimumab concentrations between $4.5-8.5 \mathrm{mg} / \mathrm{L}$ were associated with an optimal treatment response at 6 months using concentration-effect curves. Factors that were significantly associated with adalimumab drug levels were ADAb level $[\beta=-0.0073$ (95\% Cl: $-0.0014,0.18), p<0.0001]$ and BMI $[\beta=-0.15(-0.29,-0.00450, p=0.043]$ in the final GEE model (adjusting for age, gender, adherence, BMI).

Conclusions: TNFi drug-level testing in adalimumab-initiated PsA patients may be useful in determining treatment response and disability over 12 months; interestingly, both the presence of ADAbs and BMI were inversely associated with drug levels. Identification of a drug level threshold for optimal response may help tailor adalimumab therapy for PsA patients in the future.

Acknowledgements: This work was funded from a grant awarded by the National Institute of Health and Research, Manchester Musculoskeletal BRU to MJ, AB.

Disclosure of Interest: M. Jani Grant/research support from: Abbvie, UCB, Pfizer, H. Chinoy Grant/research support from: Novartis, Abbvie, Consultant for: Eli-Lilly and Novartis, Speakers bureau: UCB, A. Barton Grant/research support from: Eli-Lilly, Speakers bureau: Roche Chugai and Pfizer DOI: 10.1136/annrheumdis-2017-eular.2030

\section{OP0111 THE ASSOCIATION BETWEEN SONOGRAPHIC ENTHESITIS AND RADIOGRAPHIC JOINT DAMAGE IN PSORIATIC ARTHRITIS}

A. Polachek ${ }^{1}$, R. Cook ${ }^{2}$, V. Chandran ${ }^{1,3}$, D. Gladman ${ }^{1,3}, \underline{\text { L. Eder }}^{3,4}$. $^{1}$ Centre for Prognosis Studies in the Rheumatic Diseases, University Health Network, Toronto; ${ }^{2}$ Department of Statistics and Actuarial Science, University of Waterloo, Waterloo; ${ }^{3}$ Department of Medicine, University of Toronto; ${ }^{4}$ Women's College Research Institute, Women's College Hospital, Toronto, Canada

Background: Enthesitis is a common clinical finding and a key pathogenic feature in psoriatic arthritis (PsA). Ultrasound is emerging as a preferred method to assess enthesitis. Little is known about the relation between the presence of enthesitis and the severity of joint damage in patients with PsA.

Objectives: Our objective was to examine the association between sonographic enthesitis and the severity of radiographic features of damage in the peripheral and axial joints in PsA.

Methods: A cross-sectional study was conducted in consecutive patients with PsA. The MAdrid Sonography Enthesitis Index (MASEI) scoring system was used to quantify the extent of sonographic entheseal abnormalities in 12 entheseal sites. Total MASEI was further categorized into: bone scores (enthesophytes, erosions) and soft tissue scores (structural changes, vascularization, bursitis). Radiographic joint damage in the peripheral joints and spine was assessed independently of the ultrasound results using the modified Steinbrocker score, Modified New York Criteria for sacroiliitis and the modified Stoke Ankylosing Spondylitis Spine Score (mSASSS). Additionally, the presence of ankylosis, arthritis mutilans and periostitis in the hands or feet was determined. Linear and logistic regression models were used to assess the association between MASEI score and the radiographic features of joint damage after controlling for age, sex, BMI, PsA duration and the use of DMARDs and biologic medications.

Results: 222 patients were included ( $58 \%$ men) with mean (s.d.) age of 55.9 (12.9) years and PsA duration of 16.7 (12.4) years. The mean MASEI score was 15.6 (12.6). The mean modified Steinbrocker score was 18.1 (32.3), mSASSS was $1.7(7.3)$ and $37 \%$ had sacroiliitis. Multivariate regression analyses found an association between higher scores of MASEI scores and peripheral joint damage: modified Steinbrocker score $(\beta$ 9.26, $\mathrm{p}<0.0001$ ), joint ankylosis (Odds Ration (OR) 2.09, $\mathrm{p}=0.0001$ ) and arthritis mutilans (OR 1.73, $\mathrm{p}=0.005)$. The association between MASEI scores and periostitis was of borderline statistical significance (OR 1.29, $p=0.06$ ). Similarly, an association was found in multivariate analyses between higher MASEI scores and axial damage as measured by mSASSS ( $\beta$ $1.55, p \leq 0.0001$ ) and sacroilitis (OR 1.36, $p=0.02$ ). Sub-analysis showed that the MASEI bone score were more strongly associated with radiographic damage outcomes than the MASEI soft tissue score.

Conclusions: The severity of sonographic enthesitis is a marker of radiographic peripheral and axial joint damage in PsA. The association was found with both erosive and bone formation lesions. These findings highlight the potential role of enthesitis in the pathogenesis of articular damage in PsA.

Disclosure of Interest: None declared

DOI: 10.1136/annrheumdis-2017-eular.5007

\section{OP0112 IN PSORIATIC ARTHRITIS FATIGUE IS DRIVEN BY INFLAMMATION, DISEASE DURATION, AND CHRONIC PAIN: AN OBSERVATIONAL DANBIO REGISTRY STUDY}

M. Skougaard ${ }^{1}$, T.S. Jørgensen ${ }^{1}$, S. Rifbjerg-Madsen ${ }^{1}$, L. Coates ${ }^{2}$, A. Egeberg ${ }^{3}$, K. Amris ${ }^{1}$, L. Dreyer ${ }^{1}$, P. Højgaard ${ }^{1}$, J. Guldberg-Møller ${ }^{1}$, J.F. Merola ${ }^{4}$, P. Frederiksen ${ }^{1}$, H. Gudbergsen ${ }^{1}$, L.E. Kristensen ${ }^{1}$. ${ }^{1}$ The Parker Institute, Copenhagen University Bispebjerg and Frederiksberg, Copenhagen F, Denmark; ${ }^{2}$ Leeds Institute of Rheumatic and Musculoskeletal Medicine, University of Leeds, Leeds, United Kingdom; ${ }^{3}$ Department of Dermatology and Allergy, Copenhagen University Hospital Gentofte and Herlev, Hellerup, Denmark; ${ }^{4}$ Department of Dermatology and Department of Medicine, Devisions of Rheumatology, Brigham and Woman's Hospital, Boston, Massachusetts, United States

Background: Fatigue has been identified as one of the most significant symptoms and an outcome of great importance to patients with psoriatic arthritis (PsA), but the association between underlying components of experienced fatigue and the disease has been sparsely investigated. [1]

Objectives: To describe the degree of fatigue in a PsA population. Secondly, to explore which components of inflammation and non-inflammatory factors contribute to experienced fatigue.

Methods: The study was designed as a cross-sectional survey including patients 